\title{
Sequence Control of Grain Dryer Machine using PLC
}

\author{
Gurmeet Singh ${ }^{1}$, Dr.R.K Jarial ${ }^{2}$, Anshul Agarwal ${ }^{3}$,Satyaprakash Ram ${ }^{4}$, \\ Mithun Mondal ${ }^{5}$, Suresh Kumar Dogra ${ }^{6}$ \\ 1,2,3,4,5,6 (Electrical Engineering Department, National Institute of Technology, Hamirpur (H.P), India)
}

\begin{abstract}
In India 70 percent of the grain is sundried. This leads to increased dependence on the environment and loss of grain if improperly dried. The drying of grain by the conventional method cannot achieve the desired moisture level as per the user's requirement. The use of grain dryers will not only reduce the environmental dependence of the drying process but will also provide customizable moisture content in the grain according to user's demands. The storage of the grain requires is to be below at a particular moisture level else it would lead to the development of molds which will damage the grain. So to facilitate the storage requirement of the grain the dryers would dry the grain quickly and efficiently. A methodology is developed for drying the grains through the use of humidity sensing techniques and the use of PLC to control the entire drying procedure. Thus saving energy and catering to the user's requirements. The samples of Barley have been tested to verify the effectiveness of proposed methodology developed.
\end{abstract}

Keywords: Programmable Logic Controller (PLC), Grain dryer, Fodder based furnace, Temperature sensor, Humidity sensor.

\section{Introduction}

Drying is an important operation that can preserve grain and lower losses during storage. In India, dryers are used mainly in grain processing industries, such as in rice and pulse mills. Some dryers are being used in modern drying-cum-storage complexes. However, $70 \%$ of the grain stored is sun dried. The reasons for nonuse of dryers at farmer level are: unawareness of the importance of Grain drying; non-availability of dryers within their reach; high initial capital investment required; and lack of incentive for properly dried grain. Establishing drying-cum-storage complexes has been suggested as a possible solution. The preservation of agricultural produce by drying is a long-established technique. Sun drying in the open, on mud-plastered or concrete floors, is the conventional method of drying grain and also cash crops like chillies, and plantation and horticultural crops. The drying time required in the open sun for these crops ranges from 5 to 45 days depending upon the crop to be dried. Unfavourable weather conditions are likely to occur during the drying period and degradation in quality of the final produce therefore becomes unavoidable. It is well-known that deterioration in quality caused by improper drying cannot be eliminated until improved drying systems based on mechanical dryers have been adopted. However, for many reasons, these systems have not been adopted. The main reason that is encountered is a lack of adequate expertise about the drying technique. A second important reason for not using dryers is their high initial costs. Most of the commercially available dryers are designed to suit the needs of the processing industry and their output capacity is therefore far above the needs of individuals, or even of farmer groups.

The main objective of any drying process is to produce a dried product of desired quality at minimum cost and maximum throughput and to optimize these factors consistently [1, 2]. In the test results [3], a tempering process can increase the drying rate, reduced the energy consumption and crack rate during paddy drying. The interaction between the critical moisture content of paddy, drying rate, drying time, and hot air temperature, in which the hot air temperature is the main parameter [4]. Grain moisture changes with air temperature and relative humidity $(\mathrm{RH})$ during storage [5].

Many factories use PLCs in automation processes to diminish production cost and to increase quality and reliability [6]. The automation of Grain Drying Machine involves the use of PLC to control the sequencing of various motors. The two major requirements for automation are the sensing part and the control. The sensing involves the use of various sensors which act as the input to the PLC. The objective this paper is to develop sequential control attempts to remove inefficiency through the use of automated control technique, thus minimizing the requirement of manual expertise and also improves the drying rate. The temperature measurement is done through the use of RTD (temperature sensor) so that the grain's drying temperature doesn't exceed the prescribed limit. A humidity sensor HSM-20G is used to measure humidity of exhausted air. The outputs of these two sensors act as input to the PLC. Then controller (PLC) gives the switching commands to various motors viz. Blower motor, grain rotation motor, elevator motor and fodder cutter motor through the sequential control program entered in memory of PLC, by the user as per their requirement. 


\section{Maximum Grain Drying Temperature}

Table 1 provides maximum safe operating temperatures based on the type of grain and its end use. Very high temperatures can reduce germination, milling quality, or damage the grain, which result in a downgrading of the grains. An accurate temperature sensor should used to check the actual operating temperature of the grain dryer.

Table 1: Maximum safe temperature

\begin{tabular}{|c|c|c|c|}
\hline Grain Type & Seed or Malting & $\begin{array}{c}\text { Commercial } \\
\text { Use }\end{array}$ & Feed \\
\hline Wheat & $60^{\circ} \mathrm{C}$ & $65^{\circ} \mathrm{C}$ & $80-100^{\circ} \mathrm{C}$ \\
\hline Oats & $50^{\circ} \mathrm{C}$ & $60^{\circ} \mathrm{C}$ & $80-100^{\circ} \mathrm{C}$ \\
\hline Barley & $45^{\circ} \mathrm{C}$ & $55^{\circ} \mathrm{C}$ & $80-100^{\circ} \mathrm{C}$ \\
\hline Rye & $45^{\circ} \mathrm{C}$ & $60^{\circ} \mathrm{C}$ & $80-100^{\circ} \mathrm{C}$ \\
\hline Flax & $45^{\circ} \mathrm{C}$ & $80^{\circ} \mathrm{C}$ & $80-100^{\circ} \mathrm{C}$ \\
\hline Canola & $45^{\circ} \mathrm{C}$ & $65^{\circ} \mathrm{C}$ & - \\
\hline Peas & $45^{\circ} \mathrm{C}$ & $70^{\circ} \mathrm{C}$ & $80-100^{\circ} \mathrm{C}$ \\
\hline Mustard & $45^{\circ} \mathrm{C}$ & $60^{\circ} \mathrm{C}$ & - \\
\hline Sunflowers & $45^{\circ} \mathrm{C}$ & $50^{\circ} \mathrm{C}$ & - \\
\hline Lentils & $45^{\circ} \mathrm{C}$ & - & - \\
\hline
\end{tabular}

III. Design Of Drying Section

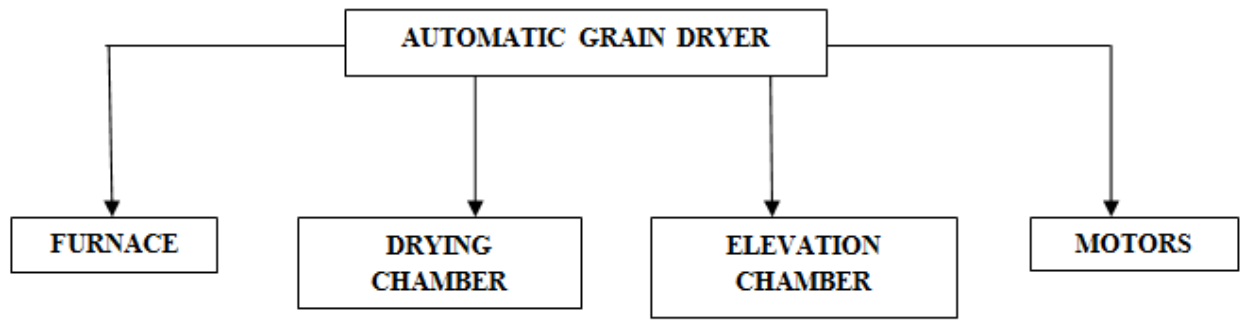

Fig. 1: Layout of drying section

Grain drying machine design consists of four section as shown in Fig. 1 and its CAD model is shown in Fig. 2, 3, 4 and 5. The machine composed of a belt drive mechanism with the buckets attached to it to take the moist grains to the drying chamber. The drying chamber itself composed of 5 stages of drying. The dimension of elevation chamber, drying chamber and bucket is shown in Table 2, 3 and 4.

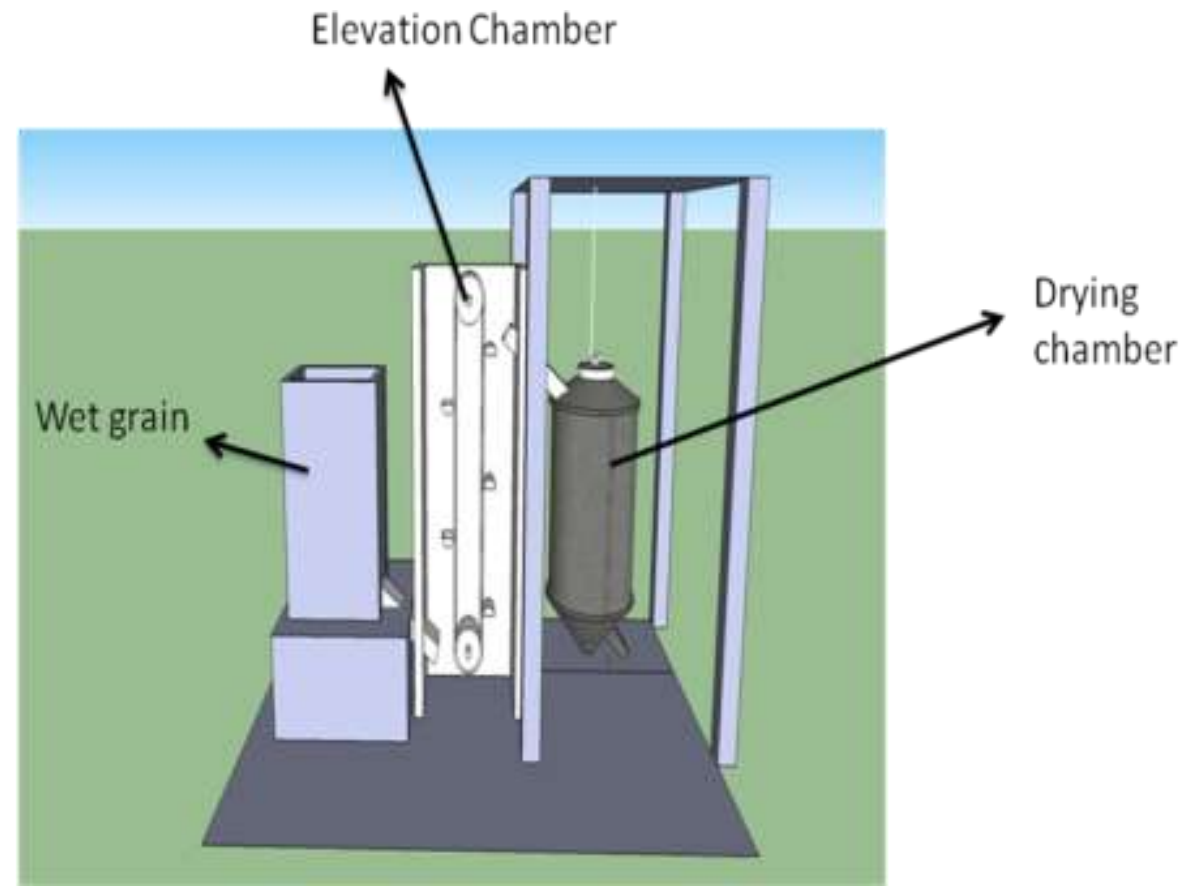

Fig. 2: Model of grain drying machine 

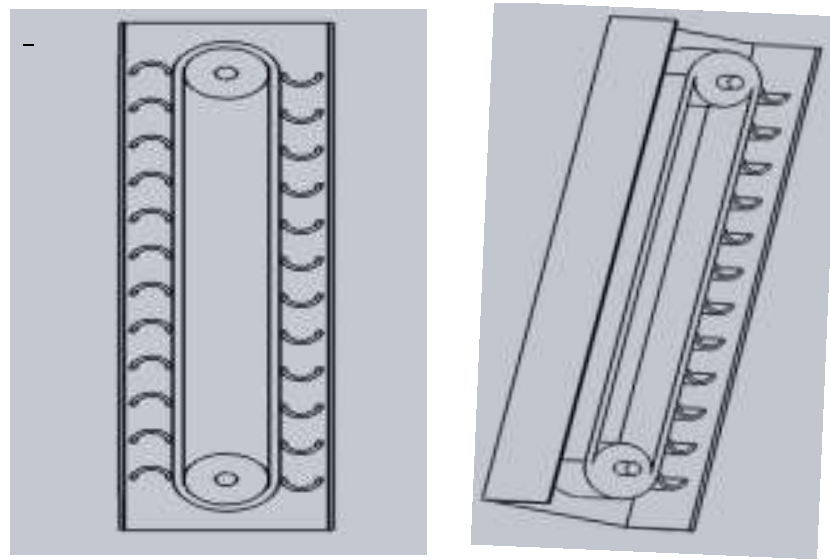

Fig. 3: Elevator chamber
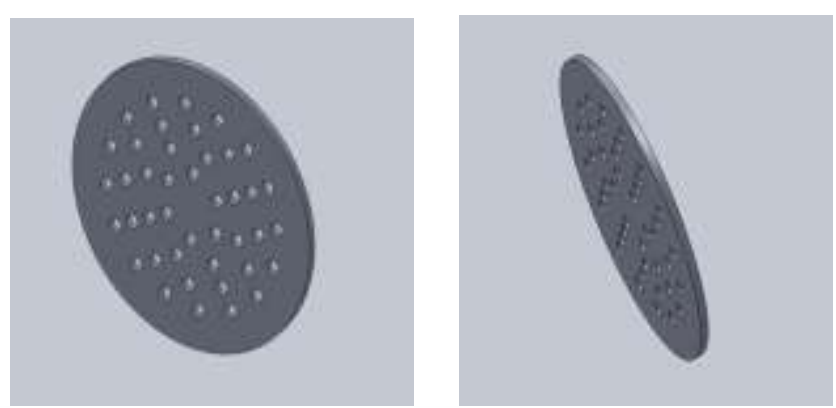

Fig. 4: Inside drying chamber

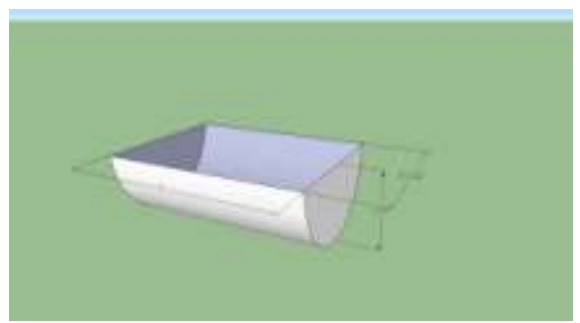

Table 4: Bucket Dimensions

\begin{tabular}{|l|l|}
\hline \multicolumn{2}{|l|}{ Bucket Dimensions } \\
\hline Length & 7inches \\
\hline Width & 5.1 inches \\
\hline Height & 2.3 inches \\
\hline
\end{tabular}

Table 2: Elevation Chamber Dimensions

\begin{tabular}{|l|l|}
\hline \multicolumn{2}{|l|}{ Elevation Chamber Dimensions } \\
\hline Length & 4ft 9inches \\
\hline Width & $1 \mathrm{ft} 3.125$ inches \\
\hline Depth & $1 \mathrm{ft} 3.125$ inches \\
\hline
\end{tabular}

\begin{tabular}{|c|c|}
\hline \multicolumn{2}{|c|}{ Drying Chamber Dimensions } \\
\hline Depth & $4 \mathrm{ft} 2$ inches \\
\hline Diameter- & $2 \mathrm{ft}$ \\
\hline Disc Hole Size- & $\begin{array}{ll}1^{\text {st }}- & 10 \mathrm{~mm} \\
2^{\text {nd }}- & 08 \mathrm{~mm} \\
3^{\text {rd }}- & 06 \mathrm{~mm} .\end{array}$ \\
\hline
\end{tabular}

Fig. 5: Bucket

Table 3: Drying Chamber Dimensions

\section{Methodology Developed}

A humidity sensor is installed inside the drying chamber of the grain dryer machine shown in Fig. 6. When the hot dry air entered the chamber it comes in contact with the moist grain in counter direction. The hot dry air flows from bottom to up and the moist grain move from top to bottom, since they move in counter direction so it behaves like a heat exchanger. During this process the wet grain becomes dry \& the dry air becomes humid as it moved up. When all the grain inside the chamber becomes dry the exhausted air humidity will be low to a steady state value or a constant value with respect to time. At that moment a signal is given to PLC which will stop the sequence of grain drying for a certain interval of time, so that the dry grain can be collected and packed. Now this process of drying sequence will again restart for a set of new moist grains.

Block diagram of automatic grain dryer is shown in Fig. 7. The algorithm used in grain drying technique is shown in Fig. 8 using flowchart. On pressing the start button the drying process begins. If the temperature of drying chamber is below $50^{\circ} \mathrm{C}$ the elevator motor and fodder cutter motor is switched on. Elevator motor is on for 1 minutes (or any time as desired by the user as per drying chamber capacity) to feed the grain into the drying chamber. If the drying chamber temperature is less than $50^{\circ} \mathrm{C}$ the grain rotation and blower motor is switched on and in the process if temperature exceeds $50^{\circ} \mathrm{C}$ the fodder cutter motor is switch off till temperature of drying chamber fall below $50^{\circ} \mathrm{C}$. When the output of humidity sensor reaches a steady state value or a constant value for certain time duration then at that stage the drying sequence is stoped. A delay is given and the process repeats itself and thus keeps on checking the input from the humidity and the temperature sensor. 


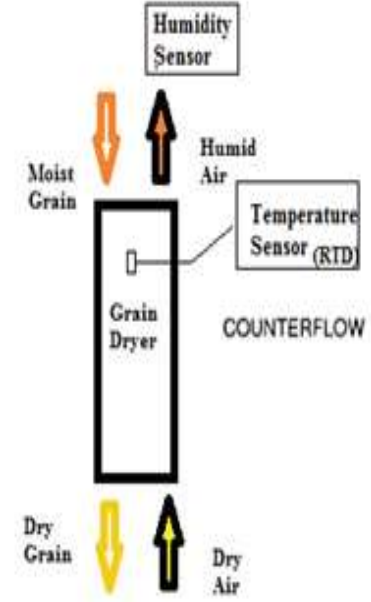

Fig. 6: Counter flow drying process.

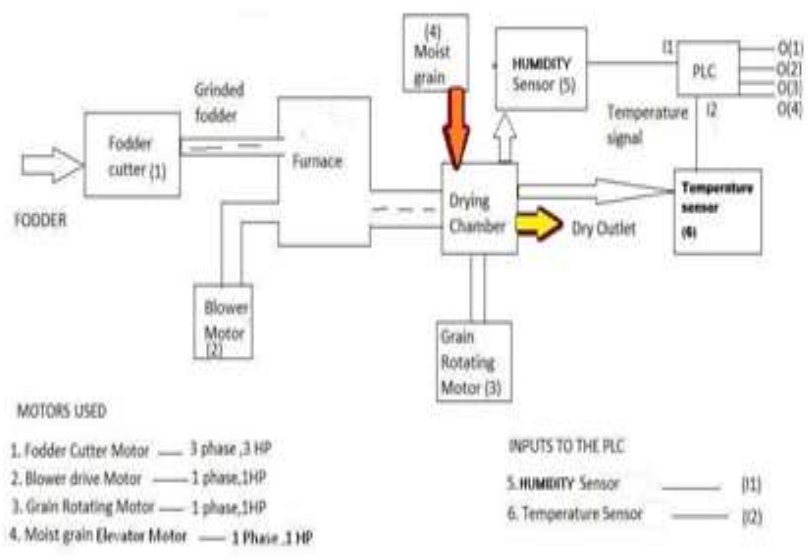

Fig. 7: Block diagram of automatic grain drying machine.

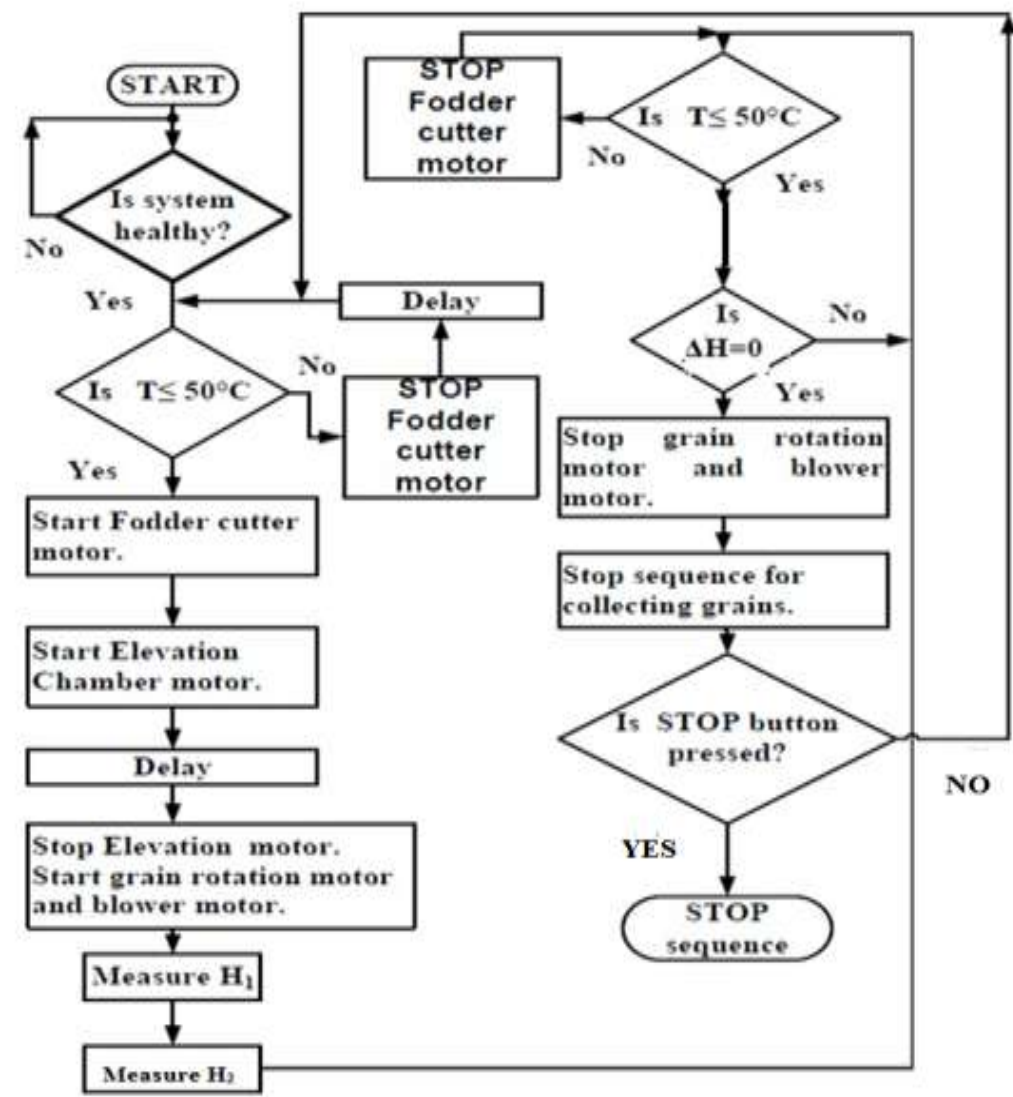

Fig. 8: Algorithm for grain drying process

\section{SENSORS AND PLC CONNECTION LAYOUT}

\subsection{Sensors:}

HSM-20G is used to measure humidity only while drying chamber temperature is measure using RTD. HSM-20G converts the relative humidity into standard voltage output. It is installed above the drying chamber of the grain dryer machine. RTD converts the temperature to Voltage output.

\subsubsection{HSM-20G Humidity Sensor}

Fig. 9 shows HSM-20G humidity sensor which converts a given air humidity to its corresponding voltage level i.e it act like a humidity to voltage sensor \& Table 5 indicates the pins and its functions [7]. Fig. 10 shows the recommended connection for the sensor to get desired output shown in Fig. 11 and Table 6. 


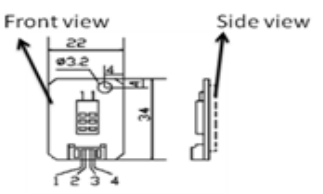

Fig. 9: HSM-20G Sensor

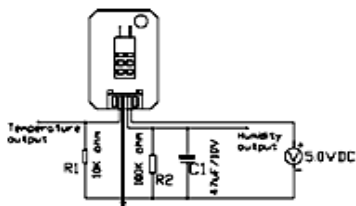

Fig. 10: Recommended connection for HSM-20G

Table 5: Pin Configuration of HSM- $20 \mathrm{G}$
\begin{tabular}{|l|l|}
\hline Pin & Function \\
\hline 1 & Temperature output \\
\hline 2 & Ground \\
\hline 3 & Humidity output \\
\hline 4 & Vcc $(+5 \mathrm{ydc})$ \\
\hline
\end{tabular}

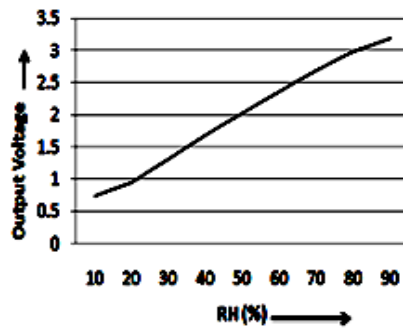

Table 6: Output Voltage with respect to $\% \mathrm{RH}$

\begin{tabular}{|l|l|l|l|l|l|l|l|l|l|}
\hline \%RH & 10 & 20 & 30 & 40 & 50 & 60 & 70 & 80 & 90 \\
\hline $\begin{array}{l}\text { Output } \\
\text { Voltage }\end{array}$ & 0.74 & 0.95 & 1.31 & 1.68 & 2.02 & 2.37 & 2.69 & 2.99 & 3.19 \\
\hline
\end{tabular}

Fig. 11: Output voltage increses linearly with increases with in $\mathrm{RH} \%$.

\subsubsection{RTD (PT100)}

It offers excellent accuracy over a wide temperature range (from -200 to $+850{ }^{\circ} \mathrm{C}$ ). Its principle of operation is to measure the resistance of a platinum element used. It has a resistance of $100 \mathrm{ohms}$ at $0{ }^{\circ} \mathrm{C}$ and 138.4 ohms at $100{ }^{\circ} \mathrm{C}$. For a PT100 sensor, a $1{ }^{\circ} \mathrm{C}$ temperature changes, will cause a $0.384 \mathrm{ohm}$ change in resistance.

\subsection{PLC Connection Layout}

We used LOGO Series PLC of Siemens shown in Fig. 12. It is a digital / analog input and digital output PLC. It has 4 digital and 4 analog inputs and all digital outputs shown in Table 7. These can be used as per the user's requirement and also can be extended using extension cards [8]

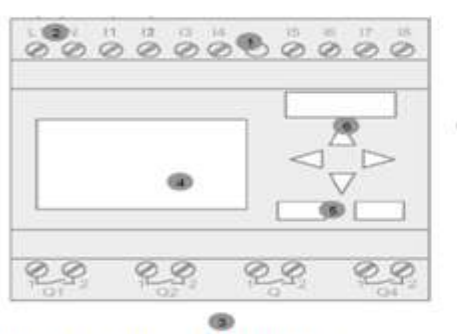

Fig. 12: Siemens Logo PLC

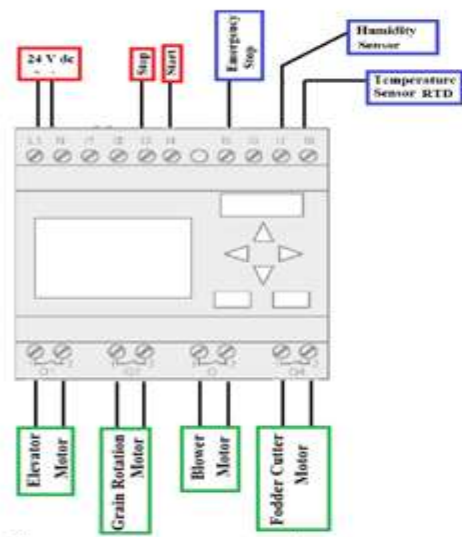

Fig. 13: PLC Connection diagram

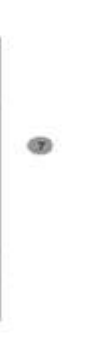

Table 7 Siemens LOGO PLC Labeling

\begin{tabular}{|c|l|}
\hline Number & Description \\
\hline 1 & $\begin{array}{l}\text { Rack with } 8 \text { inputs (I1 to I8) 4 Digital+ } 4 \\
\text { Analog }\end{array}$ \\
\hline 2 & Supply rack (L1 - N). \\
\hline 3 & Rack with 4 outputs (Q1 to Q4). \\
\hline 4 & Multi-character display screen \\
\hline 5 & Board with 6 keys \\
\hline 6 & Program cartridge compartment (optional). \\
\hline 7 & Connector for input or output expansions \\
\hline
\end{tabular}
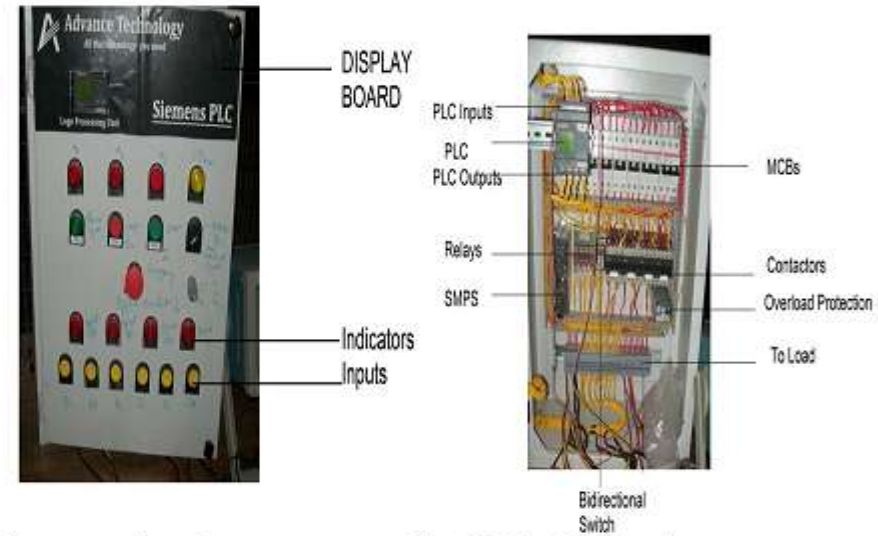

Fig. 15: Panel inner view

Fig. 14: PLC based Motor Control Panel

Fig. 13 shows layout of inputs and outputs connected to PLC and Fig. 14 shows the motor control panel used for grain dryer. Inner view of the PLC based Motor Control Panel is shown in Fig. 15 which include following components: one PLC, six MCBs, four Contactors, Relays and one SMPS. 


\section{Experimental Setup}

Fig. 16 shows the drying section of grain drying machine with elevation chamber, drying chamber and grain rotation motor. Fig. 17 shows the elevation motor which drive a pulley (in order to reduce rpm) which is further coupled with bucket conveyer in elevation chamber. Fig. 18 shows fodder cutter and a fodder based furnace.

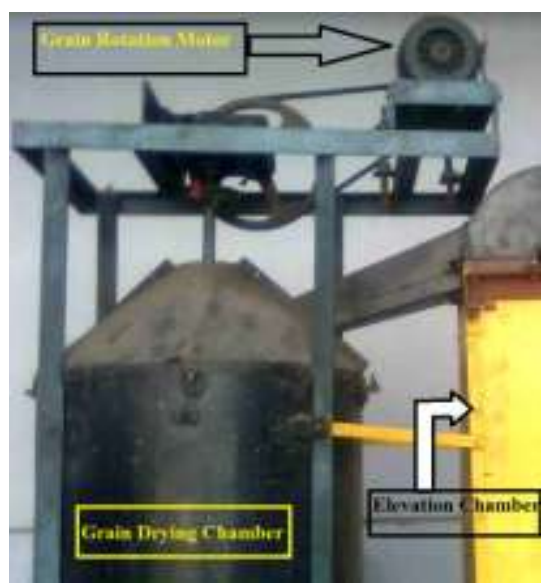

Fig. 16: Drying section

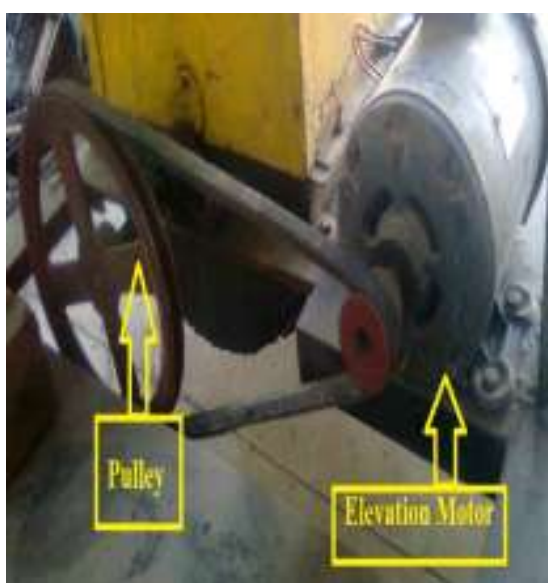

Fig. 17: Elevation chamber motor

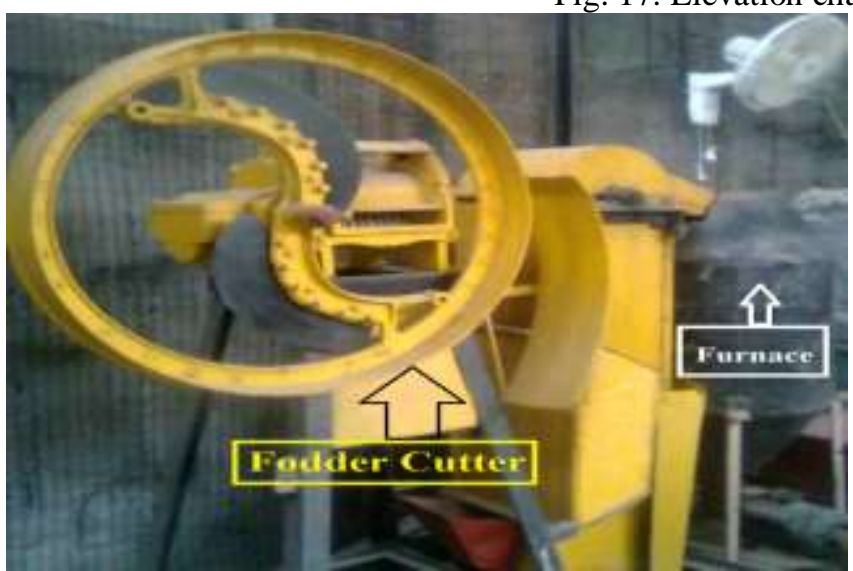

Fig. 18: Fodder cutter and furnace

\section{Test Result}

Drying reduces the amount of water contained in the crop after harvest to an acceptable level for marketing, storage, or processing. Any hygroscopic material (including grain) has its own characteristic balance between the moisture it contains and the water vapour in the air with which it is in contact. This is known as the equilibrium moisture content (EMC). When food grains containing a certain amount of moisture are exposed to air, moisture moves from the grain to the air, or vice versa, until there is a balance between the moisture in the grain and in the air.

Table 8 shows the PLC controlled automatic grain dryer test result using equations 1 and 2.

\section{Moisture Removed (MR)}

MR $\%=100 \mathrm{x}$ (wet weight - dry weight) $/$ (wet weight)

Equilibrium Moisture Content (EMC)

EMC $\%=100 \mathrm{x}$ (wet weight - dry weight $) /($ dry weight $)$ 
Table 8: Grain Dryer Test Result

\begin{tabular}{|c|c|c|c|c|}
\hline $\begin{array}{c}\text { BARLEY } \\
\text { SAMPLE }\end{array}$ & $\begin{array}{c}\text { INTIAL } \\
\text { WEIGHT } \\
(\mathbf{1 0} \mathbf{~ k g})\end{array}$ & $\begin{array}{c}\text { FINAL } \\
\text { WEIGHT } \\
(\mathbf{k g})\end{array}$ & $\begin{array}{c}\text { EMC } \\
(\boldsymbol{\%})\end{array}$ & $\begin{array}{c}\text { MOISTURE } \\
\text { REMOVED } \\
(\boldsymbol{\%})\end{array}$ \\
\hline Sample 1 & 10 & 8.94 & 11.8 & 10.6 \\
\hline Sample 2 & 10 & 8.55 & 16.9 & 14.5 \\
\hline Sample 3 & 10 & 8.44 & 18.4 & 15.6 \\
\hline Sample 4 & 10 & 7.98 & 25.2 & 20.2 \\
\hline
\end{tabular}

\section{Conclusion}

Automatic Grain Dryer uses ladder logic programming for PLC to control the sequence of operation of a grain drying machine. The timing is controlled from the inputs of the sensors, thus making the program fully customizable. This grain dryer PLC's uses output from humidity sensor to control the drying process. This Automatic Grain Dryer is an effort to contribute in the technological improvements of grain drying rather applying the conventional methods. Thus, the manual interference will reduce considerably in the age of automation and providing us the efficient results with fully automated sytems in grain drying machine.

\section{References}

[1] R. Daghigh, M.H. Ruslan, A. Zaharim and K. Sopian, Air Source Heat Pump System for Drying Application, Proceedings of the 9th WSEAS International Conference on System Science and Simulation in Engineering, 404-409, 2010.

[2] R. Daghigh, M.H. Ruslan, M.A. Alghoul, A. Zaharim and K. Sopian, Design of Nomogram to Predict Performance of Heat Pump Dryer, Proceedings of the 3rd WSEAS International Conference on Renewable Energy Sources, 277-282, 2009.

[3] Abhay Kumar Thakur, A. K. Gupta, Stationary versus fluidized-bed drying of high- moisture paddy with rest period [J]. Drying Technology, 24(11), 2006, $1143-1456$.

[4] K. M. Kundu, R. Das, A. B. Datta, et al. On the analysis of drying process [J]. Drying Technology, 23(5), 2005, 1093-1105.

[5] M. Volenik,V. Rozman, I. Kalinovic, A. Liska, B. Šimic, Influence of relative humidity and temperature on changes ingrain moisture in stored wheat and sunflower, 9th International Working Conference on Stored Product Protection.

[6] A. Hossain and S. M. Suyut, Monitoring and controlling of a real time industrial process using dynamic model control technology, Proc. IEEE Ind. Applicat. Soc. Workshop on Dynamic Modeling Control Applications for Industry, 1997, 20-25.

[7] HSM-20G humidity sensor module manual.

[8] User's guide to SIEMENS'S 'LOGO!' PLC. 